\title{
ARTICLE OPEN \\ Weak hydrological sensitivity to temperature change over land, independent of climate forcing
}

B. H. Samset (iD) ${ }^{1}$, G. Myhre (iD) ${ }^{1}$, P. M. Forster $\mathbb{D}^{2}$, Ø. Hodnebrog ${ }^{1}$, T. Andrews ${ }^{3}$, O. Boucher $\mathbb{D}^{4}$, G. Faluvegi ${ }^{5}$, D. Fläschner ${ }^{6}$, M. Kasoar $^{7}$, V. Kharin ${ }^{8}$, A. Kirkevåg 9 , J.-F. Lamarque ${ }^{10}$, D. Olivié ${ }^{9}$, T. B. Richardson ${ }^{2}$, D. Shindell $\mathbb{D}^{11}$, T. Takemura $\mathbb{D}^{12}$ and A. Voulgarakis $^{7}$

We present the global and regional hydrological sensitivity (HS) to surface temperature changes, for perturbations to $\mathrm{CO}_{2}, \mathrm{CH}_{4}$, sulfate and black carbon concentrations, and solar irradiance. Based on results from ten climate models, we show how modeled global mean precipitation increases by 2-3\% per kelvin of global mean surface warming, independent of driver, when the effects of rapid adjustments are removed. Previously reported differences in response between drivers are therefore mainly ascribable to rapid atmospheric adjustment processes. All models show a sharp contrast in behavior over land and over ocean, with a strong surface temperature-driven (slow) ocean HS of 3-5\%/K, while the slow land HS is only $0-2 \% / \mathrm{K}$. Separating the response into convective and large-scale cloud processes, we find larger inter-model differences, in particular over land regions. Large-scale precipitation changes are most relevant at high latitudes, while the equatorial HS is dominated by convective precipitation changes. Black carbon stands out as the driver with the largest inter-model slow HS variability, and also the strongest contrast between a weak land and strong sea response. We identify a particular need for model investigations and observational constraints on convective precipitation in the Arctic, and large-scale precipitation around the Equator.

npj Climate and Atmospheric Science (2018)1:20173; doi:10.1038/s41612-017-0005-5

\section{INTRODUCTION}

As the global surface temperature changes, so will patterns and rates of precipitation. ${ }^{1-3}$ Theoretically, these changes can be understood in terms of changes to the energy balance of the atmosphere, caused by introducing drivers of climate change, such as greenhouse gases, aerosols and altered insolation. ${ }^{4-6}$ Climate models, however, disagree strongly in their prediction of precipitation changes, both for historical and future emission pathways, and per degree of surface warming in idealized experiments. $^{7-10}$ The latter value, often termed the apparent hydrological sensitivity, has also been found to differ substantially between climate drivers. ${ }^{4,11-14}$ Further, there is a strong contrast between modeled and observed hydrological sensitivity (HS) values, ${ }^{15}$ though this may also be ascribed to uncertainties in the observations.

Multiple studies have found that the precipitation response to a perturbation, such as an increase in greenhouse gas concentrations, may usefully be divided into two broad categories with different scaling properties: a fast change, associated with an initial radiative and thermal reorganization of the atmospheric column combined with rapid adjustments to cloud fractions and microphysics, and a slower, response-driven change, associated with an altered global surface temperature. ${ }^{16-20}$ The slow change mainly scales with surface temperature, which in turn scales closely with top-of-atmosphere radiative forcing, while the rapid adjustments scale with the amount of additional energy absorbed through the atmospheric column. ${ }^{11-13}$ In particular, black carbon has been noted as an anthropogenic climate driver that is significantly different from the others, due mainly to its high atmospheric absorption and regionally heterogeneous radiative forcing. ${ }^{13}$

Subtracting the rapid adjustments, the slow, thermal hydrological sensitivity alone has been found to be more similar between models. ${ }^{9}$ This indicates a greater universality in the modeled connection between global surface temperature and global precipitation, than for the processes that link precipitation and rapid adjustments. As the physical mechanisms leading to surface temperature change also vary between drivers, however, it is relevant to investigate what fraction of the remaining intermodel differences in slow HS that may be ascribed to global or regional differences between climate drivers.

Recently, a range of global climate models performed idealized, global step perturbations to a range of climate drivers, as part of the Precipitation Driver and Response Model Intercomparison Project (PDRMIP). ${ }^{13,20}$ See Methods for a full list. As models performed both fully ocean-atmosphere coupled simulations and prescribed sea-surface temperature (fSST) atmospheric simulations, it is possible to extract and compare the thermal hydrological sensitivity between drivers. Here, we show both the total (sometimes labeled apparent) and slow hydrological sensitivities, globally and for land and ocean regions separately, and attempt to disentangle the differences between responses to greenhouse gases, aerosol and solar climate forcing. An initial

\footnotetext{
${ }^{1}$ CICERO Center for International Climate and Environmental Research, Oslo, Norway; ${ }^{2}$ University of Leeds, Leeds, UK; ${ }^{3}$ Met Office Hadley Centre, Exeter, UK; ${ }^{4}$ Laboratoire de Météorologie Dynamique, Institut Pierre-Simon Laplace, Université Pierre et Marie Curie/CNRS, 75005 Paris, France; ${ }^{5}$ NASA Goddard Institute for Space Studies and Center for Climate Systems Research, Columbia University, New York, NY, USA; ${ }^{6}$ Max-Planck-Institut für Meteorologie, Hamburg, Germany; ${ }^{7}$ Imperial College London, London, UK; ${ }^{8}$ Canadian

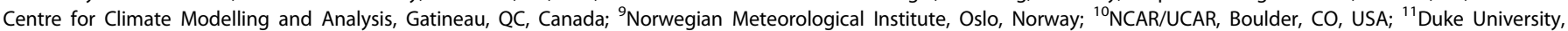
Durham, NC, USA and ${ }^{12}$ Kyushu University, Fukuoka, Japan Correspondence: B. H. Samset (b.h.samset@cicero.oslo.no)
}

Received: 24 November 2015 Revised: 2 May 2016 Accepted: 20 October 2016 Published online: 09 January 2018 
finding is that while the global mean slow HS values for different drivers are indeed similar, they vary greatly between regions.

We also study the relative contribution to the responses from modeled convective and large-scale processes, which are separately treated and differently parametrized in current generation climate models. As an example, recent literature shows that convection-permitting models yield significant improvements over parametrized treatments for reproducing climate statistics. ${ }^{21}$ We find notable differences in model diversity of convective and large-scale precipitation responses in different regions, indicating that this may be a key factor behind the previously documented inter-model differences in future precipitation changes. ${ }^{8}$

\section{RESULTS}

In the following, we will first present the global mean, multi-model hydrological sensitivities. Then we break them down into land, ocean and zonal mean responses, and study how the models subdivide the total response between convective and large-scale precipitation. For the impacts of climate change on society, relative changes to precipitation are what matters. For this reason, and to reduce reliance on differences in the baseline, we mainly show precipitation change in percent relative to the preindustrial baseline. To understand the full model treatment of precipitation, including water transport, absolute changes are also relevant. We therefore include these towards the end of the analysis.

Figure 1 shows the global, annual multi-model mean (and median) apparent and slow hydrological sensitivities. For the apparent response, we find the pattern previously shown and discussed in, ${ }^{13}$ with a stronger HS for aerosols and insolation than for greenhouse gas perturbations, and a negative response for $\mathrm{BC}$ $x$ 10. Briefly, this can be ascribed to atmospheric absorption, which tends to stabilize the atmosphere and reduce precipitation on fast timescales. Black carbon is the clearest example, where the early stabilization largely dominates over the slow, surface temperatureinduced precipitation increase. $\mathrm{CO}_{2}$ also has some degree of absorption and stabilization, while insolation and purely scattering aerosols have very little. Within the uncertainty range, we find no discernable land/ocean contrast in the apparent HS for any of the climate drivers. Note the broad inter-model spread in BC HS. The relative standard deviation (RSD, defined as the standard deviation among the ten models divided by the multi-model
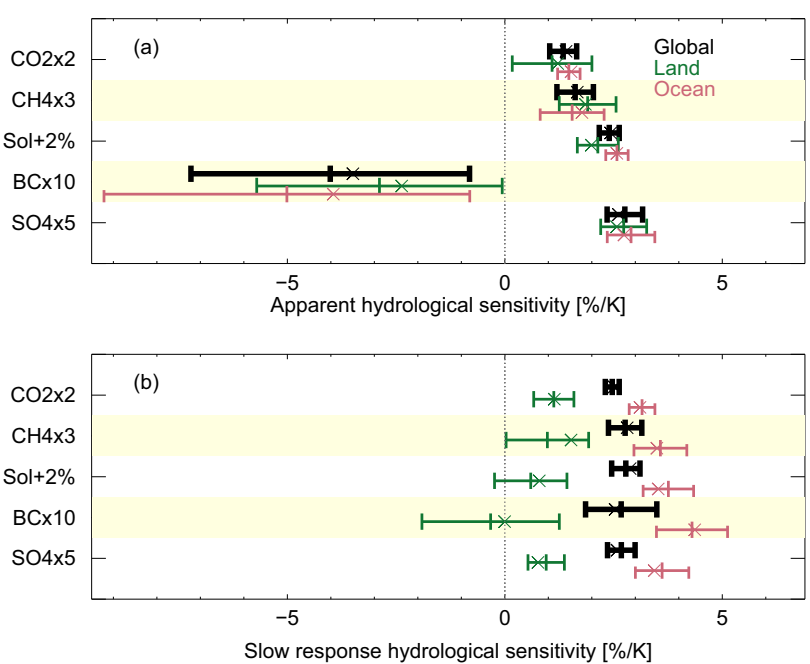

Fig. 1 Multi-model hydrological sensitivities, globally (black) and over land (green) and ocean (red) regions. a Apparent HS. b Slow HS. Error bars show one standard deviation across the model sample. Crosses indicate the multi-model median value mean) for the global mean $\mathrm{BC} \times 10$ apparent $\mathrm{HS}$ is $80 \%$, while for the other drivers it is in the range of $10-20 \%$.

Subtracting the rapid adjustments, we find the slow HS shown in Fig. $1 \mathrm{~b}$. Here, all drivers show a consistent $\mathrm{HS}$ of around $2.5 \% / \mathrm{K}$, with a RSD of $5-15 \%$ depending on the climate forcing agent, except BC $\times 10$ with an RSD of $30 \%$. Furthermore, BC $\times 10$ now yields a positive response, demonstrating the importance of the rapid adjustments for this climate driver. The land/ocean contrast in the slow $\mathrm{HS}$ is striking. Over oceans, the HS ranges from $3 \% / \mathrm{K}$ for $\mathrm{CO}_{2} \times 2$, to $4 \% / \mathrm{K}$ for $\mathrm{BC} \times 10$. Within the uncertainty range there is no indication of a stronger response for aerosols than for greenhouse gases or solar forcing. Over land, the HS ranges from $1 \% / \mathrm{K}$ for $\mathrm{CO}_{2} \times 2$ and $\mathrm{SO}_{4} \times 5$, to a multi-model mean consistent with no response for $\mathrm{BC} \times 10$. Here, however, there is significant inter-model spread, as we discuss below.

Summarizing Fig. 1, we find no significant difference between the climate drivers in their global slow, surface temperature-driven HS. There is, however, a strong land/ocean contrast, with the latter having a markedly stronger response than the former.

In Fig. 2, we show the slow HS for all models, globally and for land and ocean regions separately. We also indicate the contribution to the slow HS arising from convective precipitation, and that from large-scale clouds.

Looking first at the global response to $\mathrm{CO}_{2} \times 2$ (top, left), we note how the slow HS varies little between models, while the fraction of the slow HS from convective precipitation ranges from 12 to $92 \%$. Broadly, a model that has a high contribution from convective precipitation in its $\mathrm{CO}_{2} \times 2$ response, also has it for the other drivers, indicating that the split between precipitation types is a model-specific rather than forcing-specific feature. Two models (IPSL, CanESM2) show particularly strong contributions from large-scale precipitation. For IPSL, this can be traced to a strong, positive equatorial large-scale HS over oceans, and a broad but weaker positive HS over the Southern Ocean regions. For CanESM2, the large-scale HS is more similar in pattern to the model mean, but generally stronger. No particular feature has been identified across models with similar large-scale HS fractions that allows us to predict this split based on circulation changes or regional responses.

The ocean HS, as expected, is very similar to the global HS, as it dominates the absolute precipitation changes. Over land, the inter-model spread is markedly larger, and for most models the standard deviation of the annual means cross the zero line. Several models even show negative convective slow HS, but not with statistical significance. For $\mathrm{BC} \times 10$, the tendency is towards a strongly negative convective slow HS $(1-3 \% / K)$, in some models offset by a positive change in large-scale precipitation, such that the multi-model mean HS comes out close to zero.

In Fig. 3, we show the geographic pattern of multi-model mean HS values (corrected for the land area temperature response in the fSST simulations, see Discussion). Hatched regions on the maps indicate where the multi-model mean is more than one standard deviation away from zero. Looking first at $\mathrm{CO}_{2} \times 2$, we find a $\mathrm{HS}$ that is positive in most regions, albeit with a strength that varies from zero over some land areas, to almost $30 \% / \mathrm{K}$ in the intertropical convergence zone (ITCZ). Northern and southern Africa see a negative slow $\mathrm{HS}$, as do a range of sub-tropical regions, likely due to tropical expansion in the models. For $\mathrm{CH} 4 \times 3$, we find a very similar pattern to $\mathrm{CO}_{2} \times 2$. This response is more noisy, however, likely simply due to the weaker radiative forcing of this perturbation. ${ }^{13}$ The insolation perturbation is again very similar in pattern to $\mathrm{CO}_{2} \times 2$, including the hints of reductions in sub-tropical precipitation due to tropical expansion.

For $B C \times 10$, the pattern is very noisy, and there are very few regions with a multi-model mean more than one standard deviation away from zero. This is partly due to the weaker surface temperature change for the PDRMIP $\mathrm{BC} \times 10$ perturbation, but as this surface temperature change is comparable to the $\mathrm{CH}_{4} \times 3$ 


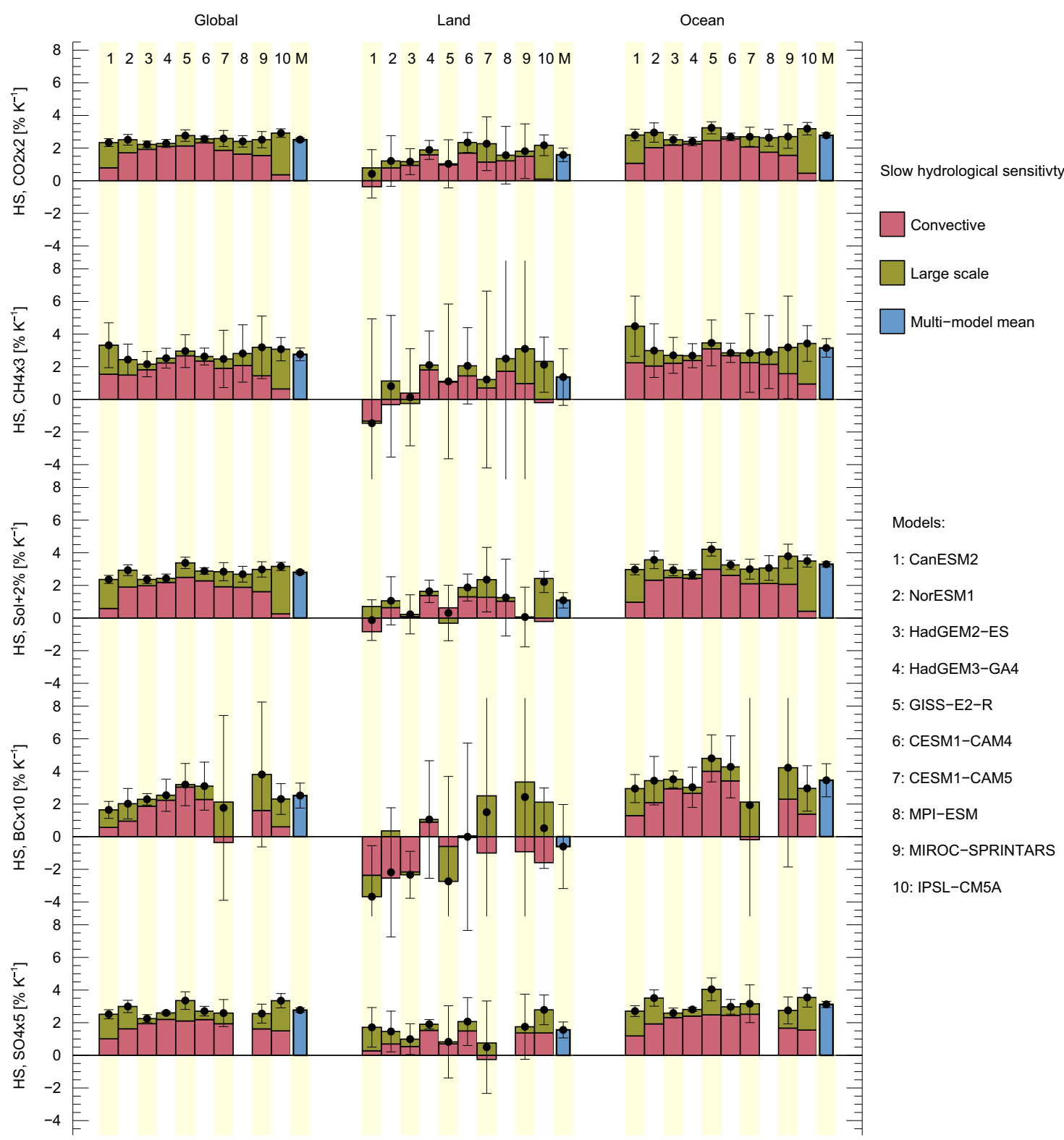

Fig. 2 Slow hydrological sensitivity in all PDRMIP models, subdivided into convective and large-scale precipitation response fractions. Columns show global, land and ocean regions, while the rows show the five climate drivers. The multi-model mean for each region and driver is shown in blue. Error bars indicate one standard deviation of the multi-model mean for the total response

case, it is unlikely to be the only reason. Rather, we here see the full effects of the inter-model differences in modeling the precipitation response to BC. See further discussion below. We discuss the main multi-model trends here, but the low significance of the results should be kept in mind.

The broad pattern of $B C \times 10$ is still similar to that found in response to greenhouse gas perturbations and the Sol $+2 \%$, but the amplitudes are larger. In particular the North African precipitation reduction is very strong, compensated by a moistening of the South-East Asian monsoon region. The Arctic/ Antarctic responses are also large, and positive. The amplitude and general variability of the slow HS pattern may also be ascribed to the weakness of the temperature response.

One pattern seen for $B C \times 10$ that differs from the greenhouse gas and solar forcings, is a notable reduction in precipitation over both the Pacific and the Atlantic just south of the Equator. A possible contributor to this is the hemispherical asymmetry in the BC perturbation. Such a feature is also seen for $\mathrm{SO}_{4} \times 5$, which imposes a similar inter-hemispheric difference. Otherwise, the sulfate forcing also exhibits a pattern similar to the other forcers both in terms of regional variations, magnitude and robustness.

Figure 4 presents the multi-model zonal mean slow HS for all drivers. In addition, we separate between land and ocean, and overlay the contributions to the HS from convective and largescale precipitation changes. This enables us to disentangle the factors contributing to the global mean results shown in Fig. $1 \mathrm{~b}$, and identify where the differences between drivers and regions originate.

Looking first at the global $\mathrm{HS}$ for $\mathrm{CO}_{2} \times 2$ (upper left), we find that the total response of $2.4 \% / \mathrm{K}$ (black) mainly arises from the equatorial and polar regions. The mid latitudes show very modest slow HS. Further, the Arctic and Antarctic responses are mainly due to changes in large-scale precipitation (red), while the changes in the equatorial region are dominated by convective precipitation (blue). However, the multi-model spread is sizeable, 

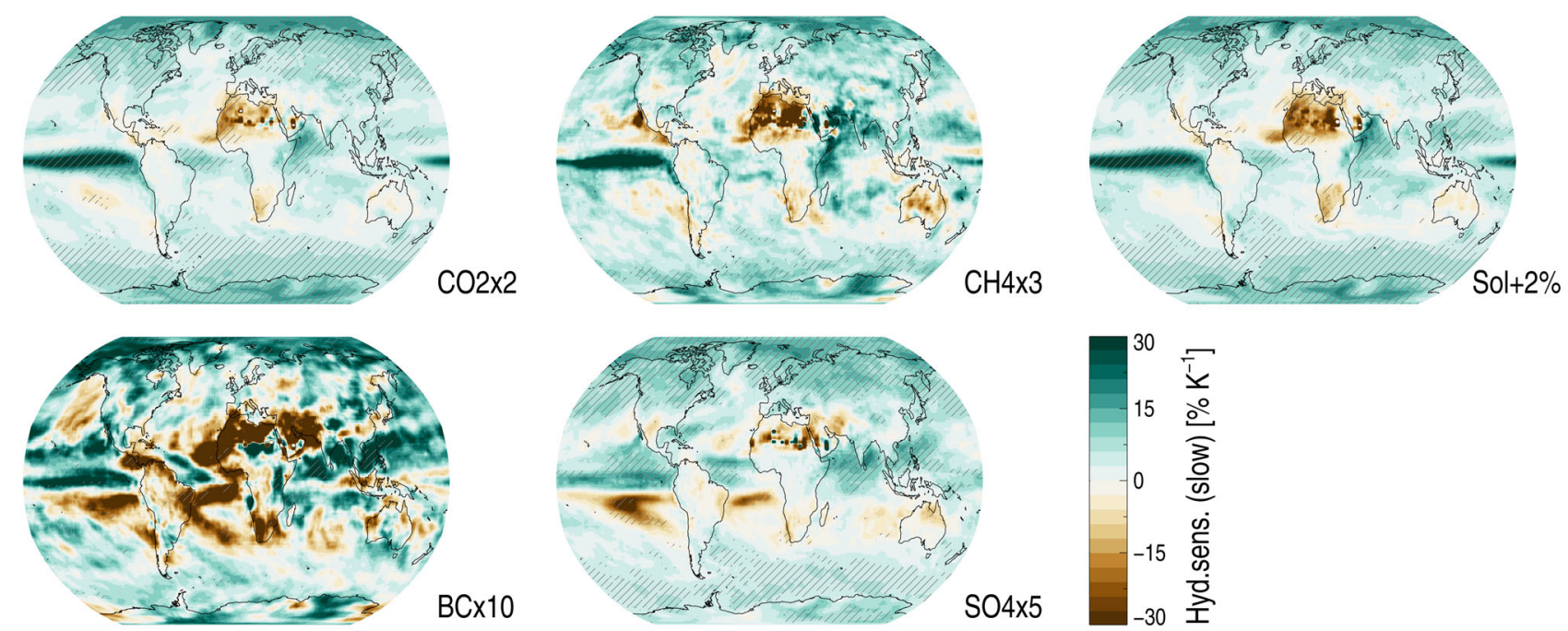

Fig. 3 Multi-model geographical pattern of slow hydrological sensitivity. Colors show the 10-model mean response. Hatched regions indicate where the multi-model mean is more than one standard deviation away from zero
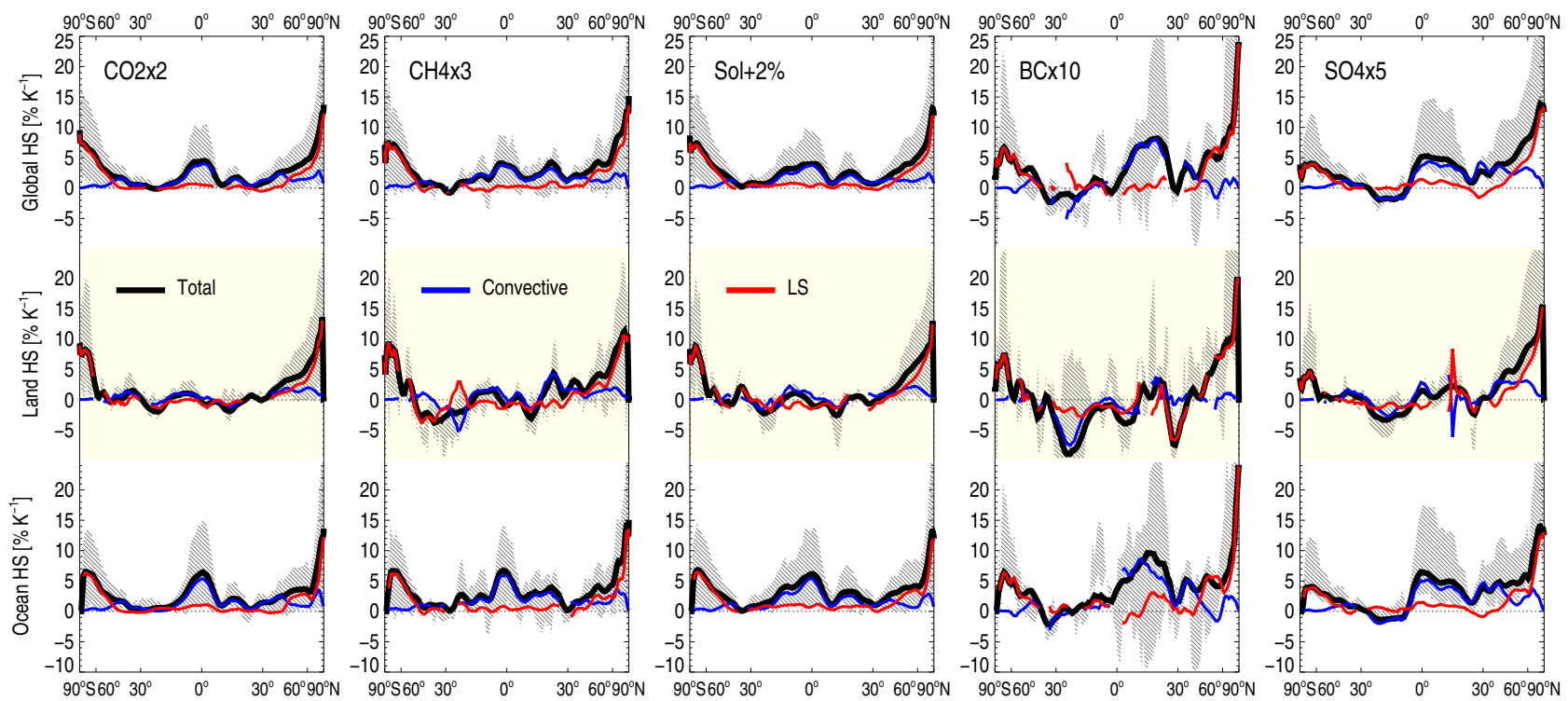

Fig. 4 Zonal mean, multi-model mean slow hydrological sensitivity, to all drivers (columns), globally (top) and for land (middle) and ocean (bottom) regions. The hatched band shows the 25 th/75th percentile range for the global response (black). The convective (blue) and largescale (red) precipitation response per kelvin of warming is also shown

as indicated by the gray hatching which shows the 25th-75th percentile range for the global HS.

Separating the global response into land and ocean (2nd and 3rd rows), we find that for a $\mathrm{CO}_{2}$ perturbation, the convective precipitation HS over land does not change, while the entire equatorial, convectively driven HS contribution comes from the ocean (ITCZ) regions. The large-scale precipitation changes in polar regions can be seen both over land and ocean. We find a slight hemispheric asymmetry in the convective response over oceans, with around $2 \% / \mathrm{K}$ at northern mid-latitudes, whereas no response is seen in the southern hemisphere.

The subsequent columns show results from the four other climate drivers perturbed in PDRMIP. Broadly, the zonal patterns for $\mathrm{CH}_{4} \times 3$ and $\mathrm{Sol}+2 \%$ follow those of $\mathrm{CO}_{2} \times 2$, with the exception of the equatorial ocean where the convective $\mathrm{HS}$ maximum for $\mathrm{Sol}+2 \%$ extends further south (a second peak at $20^{\circ}$ $\mathrm{S}$, where the greenhouse gas forcers yield little response). This appears to be the main driver behind the slightly stronger slow ocean HS for solar than for the $\mathrm{CO}_{2} \times 2$ forcing seen in Fig. $1 \mathrm{~b}$. We ascribe this to a slightly stronger warming south of the Equator in this experiment relative to the greenhouse gas perturbations (see Supplementary Fig. S1, showing the surface temperature changes), and the different way in which Sol $+2 \%$ and greenhouse gases force the climate. Given that the latter drive changes through longwave absorption, while stronger insolation mainly increases shortwave fluxes at top-of-atmosphere and at the surface, the response patterns and changes to convection can be expected to differ. We are however unable to isolate these differences with any significance in the present data set.

$B C \times 10$ has the widest inter-model range and the largest land/ ocean contrast in Fig. 1b. Figure 4 shows that the global $B C \times$ 10 slow HS is composed of a wide, positive, mainly convective precipitation change over the (mainly $\mathrm{NH}$ ) Equatorial oceans, and a negative, land-only, change around both $30^{\circ} \mathrm{N}$ and $30^{\circ} \mathrm{S}$. 

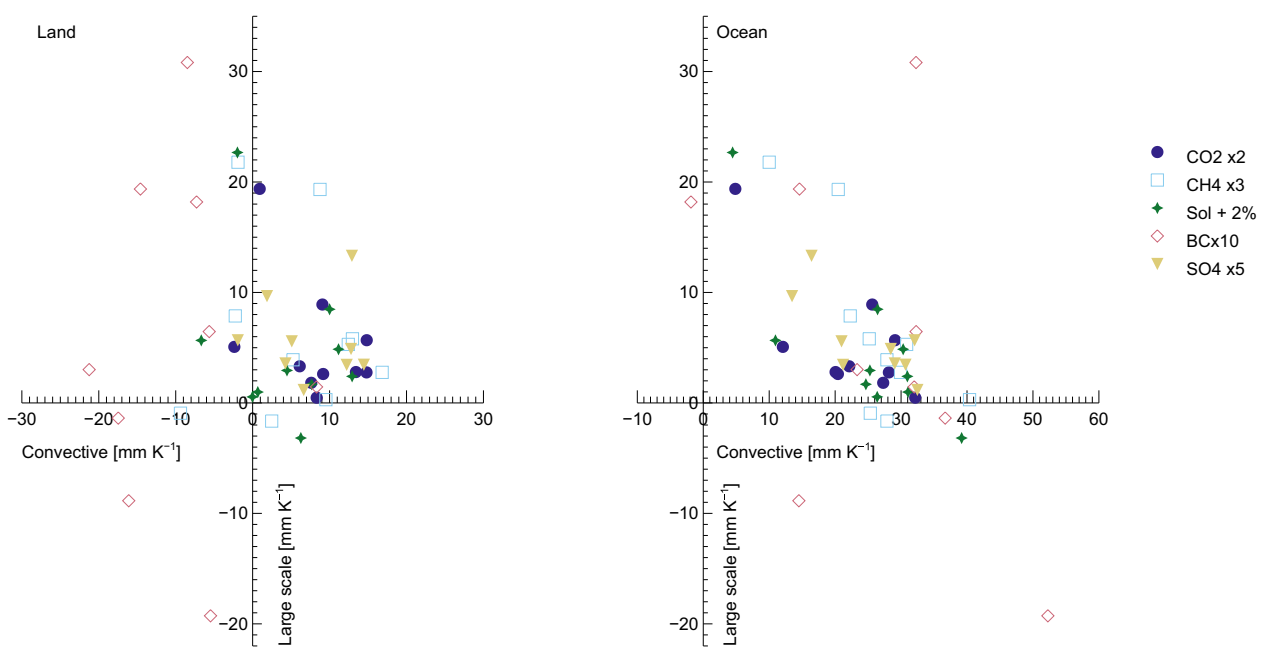

Fig. 5 Absolute slow HS ( $\mathrm{mm} / \mathrm{K}$ ) from large-scale vs. convective cloud types per kelvin of warming, for land (left) and ocean (right) regions

However, Fig. 3 indicates that there are significant regional differences behind these peaks. The multi-model variability is, in particular, driven by the ocean regions in the latitude range $0-30^{\circ} \mathrm{N}$.

SO $4 \times 5$ exhibits the strongest hemispheric asymmetry of the five drivers. Its global HS is composed mainly of a very broad $\left(0-30^{\circ} \mathrm{N}\right)$ convective response over oceans, and a northern mid latitude and high latitude $\left(>30^{\circ} \mathrm{N}\right)$ response in both cloud types over land.

Based on these findings, it is clear that there are major similarities between the slow hydrological responses to all the five drivers investigated here. However, the details show notable differences, both in regional and cloud-type response, indicating that the broad similarity seen in the global HS in Fig. $1 \mathrm{~b}$ has a nontrivial origin. One clear difference is the inhomogeneous nature of the aerosol perturbations, compared to the well-mixed greenhouse gas and insolation perturbations. Isolating any dynamical impacts on the HS solely due to this difference is however beyond the scope of the present study.

So far, we have presented relative changes in precipitation. In Fig. 5, we regress the absolute HS $(\mathrm{mm} / \mathrm{K})$ from large-scale precipitation against convective, over ocean and land regions, for all drivers and models. While there is significant inter-model diversity in all responses, some clear patterns emerge. Over land, convective clouds are found to be responsible for roughly twice the amount of precipitation change per kelvin heating that largescale clouds cause. For ocean regions, the pattern is similar except that change in convective precipitation per kelvin heating is 4-6 times as prevalent.

$B C \times 10$ is again the exception. In particular, it shows a very wide spread in predicted absolute large-scale precipitation response. Hence, developing observational constraints for large-scale precipitation change is a key challenge for models in order to reduce the multi-model diversity in $\mathrm{BC}$ precipitation response.

\section{DISCUSSION}

In ref. 13 based on the same results as in the present analysis, it was shown that for many continental regions, rapid adjustments still dominate the precipitation response even after equilibration. For the total land area, that study found a fast precipitation change fraction of up to $50 \%$ at equilibrium, depending on the climate driver, though with significant model diversity. Here, we have further shown that for land regions, the slow, temperaturedriven hydrological sensitivity is low $(0-1 \% / \mathrm{K})$. At present, we have seen close to $1 \mathrm{~K}$ of global surface temperature warming, due to a combination of greenhouse gas, aerosol, insolation and other forcing agents. ${ }^{22}$ Our results imply that the combined land area, which is where the longer observational series are available, precipitation change will be strongly affected by natural variability, and likely also rapid adjustments-in particular for regions with strong changes to $B C$ concentrations. Recent studies that have attempted detection and attribution of land area precipitation change to global warming have shown that this is possible but challenging. ${ }^{23,24}$ The low land area slow HS found here indicates that such challenges will exist for some time, at least for global land as a whole.

We have documented a clear contrast in the slow HS over land and oceans, for all five climate forcers perturbed. This difference can, to a large degree, be understood in terms of differences in the surface heating, atmospheric response to regional forcing and differences in surface relative humidity. ${ }^{25-28}$ For all forcers, the land surface temperature changes more rapidly than over the ocean (see Supplementary Fig. 1). As discussed, e.g., by Sherwood, et al. $^{19}$ this affects circulation, and is, in particular, expected to affect deep convection. ${ }^{26,29,30}$ In the present results, such a response is apparent in the zonal means in Fig. 4, for all drivers, in particular in the ITCZ regions. While there is a general increase in convective precipitation, this response is virtually absent over land. Recently, Byrne and O'Gorman ${ }^{28,31}$ have discussed the land/ ocean contrast under global warming in terms of differences in changes to relative humidity. While they find consistent fractional changes in specific humidity over land and ocean, the larger thermal response over land causes a decrease in relative humidity here, which will inhibit precipitation. The effect is amplified by the inclusion of evapotranspiration. Consistently, from an energy balance perspective, Richardson, et al. ${ }^{32}$ showed that in response to a $4 \times \mathrm{CO}_{2}$ perturbation, there is a strong flux of dry static energy $(\mathrm{H})$ from land to oceans, responsible for the main land/ocean contrast in precipitation response. The authors further decompose their $\mathrm{H}$ term into dynamic and thermodynamic contributions, and find that the dynamic term strongly dominates. While a full investigation into the dynamical and energy balance response to the PDRMIP perturbations will be presented separately, the present results indicate that the conclusions in the studies of (mainly) $\mathrm{CO}_{2}$ perturbations cited above hold across multiple drivers of climate change. For the remaining inter-model diversity in the slow hydrological response, key factors for further investigations are cloud responses ${ }^{33}$ and the role of $\mathrm{CO}_{2}$ physiological responses over land. ${ }^{34}$

Black carbon, which has previously been shown to induce a very different fast precipitation response to the other drivers in 
PDRMIP, also stands out in terms of the slow hydrological sensitivity in the present study. While the models broadly agree on both the relative and absolute changes in convective and large-scale precipitation due to the other drivers, for black carbon the response is highly diverse. While this is likely partly due to the low multi-model mean surface temperature change found for the $10 \times B C$ perturbation, differences in basic model response and individual net forcing will also contribute. As a comparison, we note that the PDRMIP $\mathrm{CH}_{4} \times 3$ perturbation is similar in top-ofatmosphere effective radiative forcing to that of the $10 \times B C$ perturbation, but that it has a much lower multi-model spread. However, as shown in Samset, et al. ${ }^{13}$ the multi-model mean atmospheric absorption for $10 \times \mathrm{BC}$ is $3.3 \mathrm{~W} \mathrm{~m}^{-2}$, but with a relative standard deviation of $40 \%$, indicating a large spread in modeled energy transferred to precipitation and other atmospheric processes. The large inter-model spread in treatment of BC microphysical effects (indirect and semi-direct effects), is also known to still be a major source for differences in precipitation response. ${ }^{35}$ The fact that four models used $B C$ emissions while five models used prescribed concentrations was however not found to be a predictive factor for the diversity in the present study.

To improve predictions of future precipitation change, a crucial first step is to identify the regions of largest diversity between present models. As an example, motivated by the assumption that $\mathrm{CO}_{2}$ is likely to be a dominating factor, ${ }^{36}$ we investigate the model spread in zonal pattern of slow HS for total precipitation, and for relative changes to convective and large-scale precipitation separately, for the $2 \times \mathrm{CO}_{2}$ perturbation. Using the mean absolute deviation (MAD) of the model sample as a measure, we compare the diversity over the equator (10S-10N), over the lower midlatitudes $(40 \mathrm{~S}-20 \mathrm{~S}, 20 \mathrm{~N}-40 \mathrm{~N})$, and the Arctic $(60 \mathrm{~N}-80 \mathrm{~N})$. For the total, slow HS, the MAD changes little, with values in the range $1.2-1.9 \% / \mathrm{K}$. For the slow HS of convective precipitation, there is a marked increase in variability towards the Arctic, with a northern mid-latitude MAD of $4.7 \% / \mathrm{K}$, and an Arctic MAD of $15 \% / \mathrm{K}$. For the slow HS of large-scale precipitation, however, MAD is low $(<2 \% / K)$ in the Arctic and at both lower mid-latitudes, but 3.5\%/K at the Equator. Modeling of Arctic convective precipitation and Equatorial large-scale precipitation, and validation against observations, are therefore highly relevant topics for future investigations, even if the corresponding slow HS is found to be low.

We note that the present analysis depends on the assumption that the fSST simulations performed capture all of the rapid adjustments and none of the surface temperature change. This is not fully justified, as land surface temperatures will, to some extent, respond even if ocean temperatures are prescribed. $\ln ^{13}$ we showed that, globally, our analysis procedure is not significantly affected $(<10 \%$ for individual models, and within statistical errors for the multi-model means). Here, we extended this analysis to include a correction for temperature increase in each grid point. Assuming a slow HS over land consistent with our global mean analysis $(1 \% / K)$, we subtract the resulting local precipitation increase from the adjustment term. This correction, which has been included in Fig. 3, changes the slow HS values by less than $10 \%$ for individual grid points, and mainly affects the inner Eurasian continent. The sensitivity to the choice of slow land $\mathrm{HS}$ is also low. Subsequent results are therefore assumed not to be significantly affected by this assumption.

We have shown that the slow, surface temperature-driven hydrological sensitivity in present climate models is broadly similar between climate drivers $(2-3 \% / K)$, but that there is a significant contrast between land and ocean, with precipitation over ocean regions responding more $(3-4 \% / K)$ than over land $(0-1 \% / K)$, across all drivers.

This low slow HS over land, combined with earlier findings of the importance of rapid adjustments, indicates that attribution of continental mean precipitation changes to different climate forcers is, and will continue to be, challenging. Regionally, the ocean response consists of an equatorial change in convective precipitation, while the land response is largest (in percentwise change) for large-scale precipitation at high latitudes.

The changes in greenhouse gases and solar insolation give rise to broadly similar slow precipitation changes, while those from aerosols stand out. Anthropogenic sulfate has a hemispherically asymmetric forcing, leading, for a positive forcing, to a displacement of the ITCZ into the northern hemisphere, with a corresponding precipitation reduction over oceanic regions that lie south of the equator, while the greenhouse gases and solar perturbation generally strengthen the existing ITCZ rainfall.

To reduce the modeled diversity in precipitation predictions, in particular for scenarios with strong radiative forcing and surface temperature change, we conclude that attention should be given to developing observational constraints on, and model validation of, large-scale precipitation processes in the Equatorial regions, and convective precipitation in the Arctic. The extra complexity added to the emerging climate response by black carbon perturbations, due to its atmospheric absorption, also requires further attention, in particular its link to large-scale precipitation change.

\section{METHODS}

We use results from ten global climate models participating in PDRMIP. ${ }^{20}$ The models separately simulated the responses to abrupt, global doubling of the $\mathrm{CO}_{2}$ concentration $\left(\mathrm{CO}_{2} \times 2\right)$, tripling of methane concentration $\left(\mathrm{CH}_{4} \times 3\right)$, five-fold increase in sulfate concentrations or sulfate-related emissions $\left(\mathrm{SO}_{4} \times 5\right)$, ten-fold increase in black carbon $(\mathrm{BC} \times 10)$, and a $2 \%$ increase in solar irradiance (Sol $+2 \%$ ).

Participating models are CanESM2, NorESM1, HadGEM2-ES, HadGEM3GA4, GISS-E2-R, IPSL-CM5A, CESM1-CAM4, CESM1-CAM5, MPI-ESM and MIROC-SPRINTARS. See Table 3 in Myhre, et al. ${ }^{20}$ for references and model details.

Mainly, the methods used in the present paper are identical to those presented in. ${ }^{13}$ For each perturbation and a baseline simulation, models provided output from 100 years of coupled/slab ocean simulations, and 15 years of prescribed, monthly-mean sea-surface temperature (fSST) simulations. The coupled simulations allow us to diagnose the total precipitation response, including both the slow temperature-driven and rapid response components, while the fSST simulations provide a good approximation of the rapid adjustments alone. Sample variance has been found to be similar for signal and background simulations. We use the terms "total" and "fast" precipitation response for these two cases, and calculate the "slow", temperature-driven response as the difference: $\Delta P_{\text {slow }}=\Delta P_{\text {total }}-\Delta P_{\text {fast }}$. The total responses are diagnosed from the last 50 years of the coupled simulations, and the fast from the last 10 years of the fSST simulations. For a discussion on our methodology for diagnosing precipitation changes, see. $^{32}$ The impacts of land area temperature response in the models for fSST are treated in the Discussion section.

The models also separately diagnosed the precipitation response due to all cloud types $\left(\Delta P^{\text {all }}\right)$, and convective processes $\left(\Delta P^{\text {conv }}\right)$. Based on these, we define a "large-scale" precipitation change as $\Delta P^{\mathrm{LS}}=\Delta P^{\text {all }}-\Delta P^{\text {conv }}$. These responses can be split into fast and slow components, just like the total response.

We diagnose the global surface temperature response to each perturbation $\left(\Delta T_{\text {glob }}\right)$ from the coupled simulations. Then, we define the hydrological sensitivity as $\mathrm{HS}=\Delta P_{\text {slow }} / \Delta T_{\text {glob }}$. We use the global temperature change even when studying the regional or zonal mean $\mathrm{HS}$, as regional changes will always be due to a combination of local and external factors when the perturbations applied are global. The total change in precipitation per degree of warming is termed the apparent hydrological sensitivity: $\mathrm{HS}_{\text {app }}=\Delta P_{\text {tot }} / \Delta T_{\text {glob }}$.

The models reported their results on a variety of spatial grid resolutions. To make multi-model maps and zonal averages, regional temperature and precipitation changes were converted to a common $1^{\circ} \times 1^{\circ}$ resolution using first-order conservative remapping. ${ }^{37}$

The median absolute deviation (MAD) used in the Discussion section is defined as $M A D=$ median $\left(\mid X_{i}\right.$-median $\left.(X) \mid\right)$, where $X_{i}$ are the individual model responses over the indicated region and $X$ is the multi-model sample. 
Data availability

All PDRMIP model results used for the present study are available to the public through the Norwegian FEIDE data storage facility. The datasets used for the figures are available upon request from the corresponding author. For more information, see cicero.uio.no/en/PDRMIP.

\section{Code availability}

Analysis code is available upon request from the corresponding author. For climate model code, refer to the corresponding authors of the references cited in Table 3 in Myhre, et al. ${ }^{20}$

\section{ACKNOWLEDGEMENTS}

B.H.S., G.M. and O.H. were funded by the Research Council of Norway, through the grant NAPEX (229778). Supercomputer facilities were generously provided by NOTUR. D.S. thanks the NASA High-End Computing Program through the NASA Center for Climate Simulation at Goddard Space Flight Center for computational resources. M.K. and A.V. are supported by the Natural Environment Research Council under grant number NE/K500872/1. Simulations with HadGEM3-GA4 were performed using the MONSooN system, a collaborative facility supplied under the Joint Weather and Climate Research Programme, which is a strategic partnership between the Met Office and the Natural Environment Research Council. T. T. was supported by the supercomputer system of the National Institute for Environmental Studies, Japan, the Environment Research and Technology Development Fund (S-12-3) of the Ministry of the Environment, Japan and JSPS KAKENHI Grant Number JP15H01728 and JP15K12190. D.J.L.O. and A.K. were supported by the Norwegian Research Council through the projects EVA (grant no. 229771) and EarthClim (207711/E10), and NOTUR (nn2345k) and NorStore (ns2345k) projects. T.R. was supported by NERC training award NE/K007483/1, and acknowledges use of the MONSooN system. Computing resources for J.F.L. (ark:/85065/d7wd3xhc) were provided by the Climate Simulation Laboratory at NCAR's Computational and Information Systems Laboratory, sponsored by the National Science Foundation and other agencies. Computing resources for the simulations with the MPI model were provided by the German Climate Computing Center (DKRZ), Hamburg. Computing resources for O.B. were provided by GENCI (project gencmip6). T.A. was supported by the Newton Fund through the Met Office Climate Science for Service Partnership Brazil (CSSP Brazil).

\section{AUTHOR CONTRIBUTIONS}

B.H.S. performed the analysis, wrote the paper and contributed model data. G.M., P.F. B.H.S. and O.H. designed the study and led the collaboration. T.A., O.B., G.F., D.F., M.K., V.K., A.K., J.F.L., D.O., T.R., D.S., T.T. and A.V. contributed model data. All authors contributed to the discussions in the paper.

\section{ADDITIONAL INFORMATION}

Supplementary information accompanies the paper on the npj Climate and Atmospheric Science website (https://doi.org/10.1038/s41612-017-0005-5).

Competing interests: The authors declare that they have no competing financial interests.

Publisher's note: Springer Nature remains neutral with regard to jurisdictional claims in published maps and institutional affiliations.

Change history: The original version of this Article had an incorrect Article number of 3 and an incorrect Publication year of 2017. These errors have now been corrected in the PDF and HTML versions of the Article.

\section{REFERENCES}

1. Held, I. M. \& Soden, B. J. Robust responses of the hydrological cycle to global warming. J. Clim. 19, 5686-5699 (2006).

2. Hartmann, D. L. et al. in Climate Change 2013: The Physical Science Basis. Contribution of Working Group I to the Fifth Assessment Report of the Intergovernmental Panel on Climate Change (eds Stocker, T. F., Qin, D., Plattner, G.-K., Tignor, M., Allen, S.K., Boschung, J., Nauels, A., Xia, Y., Bex, V. \& Midgley, P.M.) Ch. 2, 159-254 (Cambridge University Press, Cambridge, UK and New York, NY, USA, 2013).

3. Thorpe, L. \& Andrews, T. The physical drivers of historical and 21 st century global precipitation changes. Environ. Res. Lett. 9, 064024 (2014).
4. Allen, M. R. \& Ingram, W. J. Constraints on future changes in climate and the hydrologic cycle. Nature 419, 224-232 (2002).

5. O'Gorman, P., Allan, R., Byrne, M. \& Previdi, M. Energetic constraints on precipitation under climate change. Surv. Geophys. 33, 585-608 (2012).

6. Pendergrass, A. G. \& Hartmann, D. L. The atmospheric energy constraint on global-mean precipitation change. J. Clim. 27, 757-768 (2013).

7. Collins, M. et al. in Climate Change 2013: The Physical Science Basis. Contribution of Working Group I to the Fifth Assessment Report of the Intergovernmental Panel on Climate Change (eds Stocker T. F, Qin, D, Plattner, G.-K, Tignor, M, Allen, S.K., Boschung, J., Nauels, A., Xia, Y., Bex, V. \& Midgley, P.M.) Ch. 12, 1029-1136 (Cambridge University Press, Cambridge, UK and New York, NY, USA, 2013).

8. Knutti, R. \& Sedláček, J. Robustness and uncertainties in the new CMIP5 climate model projections. Nat. Clim. Change 3, 369-373 (2012).

9. Fläschner, D., Mauritsen, T. \& Stevens, B. Understanding the intermodel spread in global-mean hydrological sensitivity. J. Clim. 29, 801-817 (2016).

10. Hegerl, G. C. et al. Challenges in quantifying changes in the global water cycle. Bull. Am. Meteorol. Soc. 96, 1097-1115 (2014).

11. Andrews, T., Forster, P. M., Boucher, O., Bellouin, N. \& Jones, A. Precipitation, radiative forcing and global temperature change. Geophys. Res. Lett. https://doi. org/10.1029/2010gl043991 (2010).

12. Kvalevåg, M. M., Samset, B. H. \& Myhre, G. Hydrological sensitivity to greenhouse gases and aerosols in a global climate model. Geophys. Res. Lett. 40, 1432-1438 (2013).

13. Samset, B. H. et al. Fast and slow precipitation responses to individual climate forcers: a PDRMIP multimodel study. Geophys. Res. Lett. 43, 2782-2791 (2016).

14. Kirkevåg, A., Iversen, T., Kristjànsson, J. E., Seland, Ø. \& Debernard, J. B. On the additivity of climate response to anthropogenic aerosols and $\mathrm{CO} 2$, and the enhancement of future global warming by carbonaceous aerosols. Tellus $A \mathbf{6 0}$, 513-527 (2008).

15. DelSole, T., Yan, X. \& Tippett, M. K. Inferring aerosol cooling from hydrological sensitivity. J. Clim. 29, 6167-6178 (2016).

16. Boucher, O. et al. in Climate Change 2013: The Physical Science Basis. Contribution of Working Group I to the Fifth Assessment Report of the Intergovernmental Panel on Climate Change (eds Stocker, T. F, Qin, D., Plattner, G.-K., Tignor, M., Allen, S.K., Boschung, J., Nauels, A., Xia, Y., Bex, V. \& Midgley, P.M.) Ch. 7, 571-658 (Cambridge University Press, Cambridge, UK and New York, NY, USA, 2013).

17. Cao, L., Bala, G., Zheng, M. \& Caldeira, K. Fast and slow climate responses to $\mathrm{CO} 2$ and solar forcing: a linear multivariate regression model characterizing transientclimate change. J. Geophys. Res. Atmos. 120, 12,037-012,053 (2015).

18. Kamae, Y. \& Watanabe, M. Tropospheric adjustment to increasing CO2: its timescale and the role of land-sea contrast. Clim. Dyn. 41, 3007-3024 (2012).

19. Sherwood, S. C. et al. Adjustments in the forcing-feedback framework for understanding climate change. B. Am. Meteorol. Soc. 96, 217-228 (2015).

20. Myhre, G. et al. PDRMIP: a precipitation driver and response model intercomparison project, protocol and preliminary results. Bull. Am. Meteorol. Soc. 98 1185-1198 (2017).

21. Prein, A. F. et al. A review on regional convection-permitting climate modeling: demonstrations, prospects, and challenges. Rev. Geophys. 53, 323-361 (2015).

22. Myhre, G. et al. Anthropogenic and Natural Radiative Forcing. In Climate Change 2013: The Physical Science Basis. Contribution of Working Group I to the Fifth Assessment Report of the Intergovernmental Panel on Climate Change (eds Stocker, T. F., Qin, D., Plattner, G.-K., Tignor, M., Allen, S.K., Boschung, J., Nauels, A., Xia, Y, Bex, V. \& Midgley, P.M.) (Cambridge University Press, Cambridge and New York, NY, 2013).

23. Zhang, $X$. et al. Detection of human influence on twentieth-century precipitation trends. Nature 448, 461-465 (2007).

24. Wu, P., Christidis, N. \& Stott, P. Anthropogenic impact on Earth's hydrological cycle. Nat. Clim. Change 3, 807-810 (2013).

25. Joshi, M. M., Gregory, J. M., Webb, M. J., Sexton, D. M. H. \& Johns, T. C. Mechanisms for the land/sea warming contrast exhibited by simulations of climate change. Clim. Dyn. 30, 455-465 (2008)

26. Merlis, T. M. Direct weakening of tropical circulations from masked $\mathrm{CO}_{2}$ radiative forcing. Proc. Natl. Acad. Sci. 112, 13167-13171 (2015).

27. Dong, B., Gregory, J. M. \& Sutton, R. T. Understanding land-sea warming contrast in response to increasing greenhouse gases. Part I: transient adjustment. J. Clim. 22, 3079-3097 (2009).

28. Byrne, M. P. \& O'Gorman, P. A. Understanding decreases in land relative humidity with global warming: conceptual model and GCM simulations. J. Clim. 29, 9045-9061 (2016).

29. Fasullo, J. A mechanism for land-ocean contrasts in global monsoon trends in a warming climate. Clim. Dyn. 39, 1137-1147 (2012).

30. Endo, H. \& Kitoh, A. Thermodynamic and dynamic effects on regional monsoon rainfall changes in a warmer climate. Geophys. Res. Lett. 41, 1704-1711 (2014). 
31. Byrne, M. P. \& O'Gorman, P. A. Link between land-ocean warming contrast and surface relative humidities in simulations with coupled climate models. Geophys. Res. Lett. 40, 5223-5227 (2013)

32. Richardson, T. B., Forster, P. M., Andrews, T. \& Parker, D. J. Understanding the rapid precipitation response to $\mathrm{CO} 2$ and aerosol forcing on a regional scale. $J$. Clim. 29, 583-594 (2016).

33. Kamae, Y., Watanabe, M., Ogura, T., Yoshimori, M. \& Shiogama, H. Rapid adjustments of cloud and hydrological cycle to increasing $\mathrm{CO}_{2}$ : a review. Curr. Clim. Change Rep. 1, 103-113 (2015)

34. Cao, L., Bala, G., Caldeira, K., Nemani, R. \& Ban-Weiss, G. Importance of carbon dioxide physiological forcing to future climate change. Proc. Natl. Acad. Sci. USA 107, 9513-9518 (2010).

35. Bond, T. C. et al. Bounding the role of black carbon in the climate system: a scientific assessment. J. Geophys. Res. Atmos. 118, 5380-5552 (2013).

36. Myhre, G., Boucher, O., Breon, F.-M., Forster, P. \& Shindell, D. Declining uncertainty in transient climate response as $\mathrm{CO}_{2}$ forcing dominates future climate change. Nat. Geosci. 8, 181-185, (2015).

37. Jones, P. W. First- and second-order conservative remapping schemes for grids in spherical coordinates. Mon. Weather Rev. 127, 2204-2210 (1999). cc) (i)

Open Access This article is licensed under a Creative Commons Attribution 4.0 International License, which permits use, sharing, adaptation, distribution and reproduction in any medium or format, as long as you give appropriate credit to the original author(s) and the source, provide a link to the Creative Commons license, and indicate if changes were made. The images or other third party material in this article are included in the article's Creative Commons license, unless indicated otherwise in a credit line to the material. If material is not included in the article's Creative Commons license and your intended use is not permitted by statutory regulation or exceeds the permitted use, you will need to obtain permission directly from the copyright holder. To view a copy of this license, visit http://creativecommons. org/licenses/by/4.0/.

(c) The Author(s) 2018 